\title{
1997-2007 CO trend at the high Alpine site Jungfraujoch: a comparison between NDIR surface in situ and FTIR remote sensing observations
}

\author{
B. Dils ${ }^{1}$, J. Cui ${ }^{2}$, S. Henne ${ }^{3}$, E. Mahieu ${ }^{4}$, M. Steinbacher ${ }^{3}$, and M. De Mazière ${ }^{1}$ \\ ${ }^{1}$ Belgian Institute for Space Aeronomy, Brussels, Belgium \\ ${ }^{2}$ Institute for Atmospheric and Climate Science, ETH Zürich, Switzerland \\ ${ }^{3}$ Empa, Swiss Federal Laboratories for Materials Science and Technology, Dübendorf, Switzerland \\ ${ }^{4}$ Institute of Astrophysics and Geophysics, University of Liège, Liège, Belgium
}

Received: 4 March 2011 - Published in Atmos. Chem. Phys. Discuss.: 16 March 2011

Revised: 11 June 2011 - Accepted: 29 June 2011 - Published: 13 July 2011

\begin{abstract}
Within the atmospheric research community, there is a strong interest in integrated datasets, combining data from several instrumentations. This integration is complicated by the different characteristics of the datasets, inherent to the measurement techniques. Here we have compared two carbon monoxide time series (1997 till 2007) acquired at the high-Alpine research station Jungfraujoch $(3580 \mathrm{~m}$ above sea level), with two well-established measurement techniques, namely in situ surface concentration measurements using Non-Dispersive Infrared Absorption technology (NDIR), and ground-based remote sensing measurements using solar absorption Fourier Transform Infrared spectrometry (FTIR). The profile information available in the FTIR signal allowed us to extract an independent layer with a top height of $7.18 \mathrm{~km}$ above sea level, appropriate for comparison with our in situ measurements. We show that, even if both techniques are able to measure free troposphere $\mathrm{CO}$ concentrations, the datasets exhibit marked differences in their overall trends $\left(-3.21 \pm 0.03\right.$ ppb year $^{-1}$ for NDIR vs. $-0.8 \pm 0.4$ ppb year $^{-1}$ for FTIR). Removing measurements that are polluted by uprising boundary layer air has a strong impact on the NDIR trend (now $-2.62 \pm 0.03$ ppb year $^{-1}$ ), but its difference with FTIR remains significant. Using the LAGRANTO trajectory model, we show that both measurement techniques are influenced by different source regions and therefore are likely subject to exhibit significant differences in their overall trend behaviour. However the observation that the NDIR-FTIR trend difference is as significant before as after 2001 is at odds with available emission databases which claim a significant Asian CO increase after 2001 only.
\end{abstract}

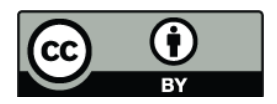

Correspondence to: B. Dils (bart.dils@bira-iasb.be)

\section{Introduction}

Carbon monoxide $(\mathrm{CO})$ is mainly produced by incomplete combustion of carbon-containing materials (fossil fuels or biomass) and plays an important role in tropospheric chemistry. Its reaction with the hydroxyl radical $(\mathrm{OH})$ is widely considered as its most important sink, and at the same time it is also the dominant reaction partner for $\mathrm{OH}$ (barring strongly polluted or forested areas) (Logan et al., 1981). As such, CO has a strong indirect impact on the growth rates of many important greenhouse gases such as $\mathrm{CH}_{4}$ and $\mathrm{O}_{3}$ (Daniel and Solomon, 1998; Wild and Prather, 2000; Levy et al., 1997). It also has a direct influence on $\mathrm{CO}_{2}$ through its oxidation.

Therefore accurate long-term measurements of tropospheric $\mathrm{CO}$ concentrations are important as they improve our understanding of the earth's past, present and future atmosphere. While the usage of space-borne instruments such as MOPITT, SCIAMACHY and IASI have become increasingly important for measuring the atmospheric composition on a global scale, their use for long-term trend analysis is often hampered by system degradation and drifts (Deeter et al., 2010). Thus ground-based measurements are vital for providing very accurate and consistent data with high temporal resolution over extended periods of time, ideally suited for satellite validation and trend analysis purposes. The downside of in situ measurements is their limited spatial coverage. The size of the area for which a station is representative depends on a multitude of parameters such as the site's location and lifetime of the target species in question (Henne et al., 2010; Folini et al., 2009). CO is particularly interesting in this respect as its global average lifetime is about two months, although the range is considerable: 10-15 days in summer over continents and up to a year in winter at high

Published by Copernicus Publications on behalf of the European Geosciences Union. 
latitudes (Holloway et al., 2000). This implies that it can be transported over long intercontinental distances, while at the same time its lifetime is too short for it being well mixed throughout the troposphere in both hemispheres. These properties make $\mathrm{CO}$ an ideal element in tracer studies, but they also potentially make the observed $\mathrm{CO}$ concentrations particularly sensitive to the measurement location. Indeed Zellweger et al. (2009) compared surface in situ CO measurements from several Swiss stations and noticed a clear dependence of the long-term $\mathrm{CO}$ trend on the altitude of the station. Barret et al. (2003) already performed a comparison between $\mathrm{CO}$ measurements from solar absorption Fourier transform Infrared Spectrometry (FTIR), MOPITT and Non-Dispersive Infrared Absorption technology (NDIR) at Jungfraujoch for the period between 1997 and 2000. For this limited time period they found a good correlation and no significant bias between NDIR and "surface" FTIR, defined as the 3.58-6.5 km layer.

With 11 years of data available now, we will revisit this comparison, focusing on the observed FTIR and NDIR longterm trends between 1997 and 2007 and assess whether two different measurement techniques at the same site could also harbour strong inherent differences, due to the above mentioned properties of $\mathrm{CO}$.

\section{Study site Jungfraujoch}

The high-Alpine research station Jungfraujoch (JFJ, $46.5^{\circ} \mathrm{N}$, $8^{\circ} \mathrm{E}, 3580 \mathrm{~m}$ above sea level) is situated on a mountain saddle between the Jungfrau ( $4158 \mathrm{~m}$ a.s.l.) and Mönch ( 4099 m a.s.l.) peaks, on the northern edge of the Swiss Alps. Due to its unique location, the year-round accessibility, and the excellent infrastructure, the Jungfraujoch research station is well suited for long-term ground-based monitoring of trace gas mixing ratio trends in the free troposphere. However, the site is also intermittently influenced by polluted boundary layer air (Zellweger et al., 2003) reaching the site during föhn or thermally-induced vertical transport conditions (Henne et al., 2004). The area influencing JFJ was recently compared with other European background monitoring sites and the site was categorized as "mostly remote" (Henne et al., 2010). Continuous ground-based in situ trace gas measurements are performed as part of the Swiss National Air Pollution Monitoring Network (NABEL). The long-term groundbased remote sensing observations are conducted as part of the Network for the Detection of Atmospheric Composition Change (NDACC), formerly the Network for the Detection of Stratospheric Change (NDSC). Meteorological parameters are measured by the Swiss Federal Office of Meteorology and Climatology (MeteoSwiss). The station is one of the 27 global stations of the Global Atmosphere Watch (GAW) of the World Meteorological Organization (WMO).

\section{Experimental systems}

\subsection{NDIR measurements at Jungfraujoch}

Continuous ground-based in situ $\mathrm{CO}$ measurements have been performed by the Swiss Federal Laboratories for Materials Science and Technology (Empa) as part of the NABEL network since April 1996. These measurements have been performed with a commercial instrument (Horiba APMA360, Kyoto, Japan) using Cross Flow Modulated NonDispersive Infrared Absorption technology. Sample gas and reference gas are injected alternately ( $1 \mathrm{~Hz}$ frequency) into the measurement cell using solenoid valve modulation. Sample air is taken to generate $\mathrm{CO}$-free reference gas by using a catalyst to oxidize $\mathrm{CO}$ to $\mathrm{CO}_{2}$. Since the same gas is used for both the sample gas and the reference gas, zero drifts and interference effects are minimized. The sample air is dried using an additional Nafion drier to reduce potential water vapour interferences.

A zero check of the instrument is performed every $49 \mathrm{~h}$ using externally generated zero air by means of a $\mathrm{CO} / \mathrm{CO}_{2}$ converter, molecular sieve $3 \AA$ and metal catalysts to convert $\mathrm{CO}$ (SOFNOCAT). Calibration of the instrument is performed twice a month using $\mathrm{CO}$ standards in the low-ppm range that are calibrated against NIST (National Institute of Standards and Technology, USA) and NMI (Nederlands Meetinstituut, The Netherlands) standards. The detection limit (zero $+3 \sigma$ of the zero signal) is about $30 \mathrm{ppbv}$. A complete service check is performed once per year by the Swiss Horiba sales and service company (Deltatech, Switzerland).

Data are routinely recorded as $10 \mathrm{~min}$ averages. The overall measurement uncertainty for these values is estimated to be $<10 \%$ below $100 \mathrm{ppbv}$ and $<5 \%$ above $100 \mathrm{ppbv}$.

\subsection{FTIR observations at Jungfraujoch}

Pioneering ground-based infrared measurements have been performed at the Jungfraujoch by the University of Liège (ULg) in the early 1950s (Zander et al., 1989, 2008). Regular FTIR measurements started in 1984 using a homemade instrument, backed since 1990 by a commercial Bruker IFS$120 \mathrm{HR}$ spectrometer. We considered here the Bruker time series of CO vertical profile data covering the 1997-2007 time period; it is part of the 1989-2010 dataset publicly available in the database of the Network for the Detection of Atmospheric Composition Change (NDACC) (see http: //www.ndacc.org).

For the retrieval, the SFIT2 (v3.91) algorithm was used; it is based on the Optimal Estimation Method (OEM) as described by Rodgers (1976). The spectroscopic parameters of the absorption lines have been taken from the HITRAN2004 database (Rothman et al., 2003), including all the August 2006 updates (http://www.hitran.com). Three microwindows were simultaneously fitted, with limits ranging from 2057.7 to $2058 \mathrm{~cm}^{-1}, 2069.56$ to $2069.76 \mathrm{~cm}^{-1}$ and 
2157.3 to $2159.15 \mathrm{~cm}^{-1}$, respectively. Interferences by the solar spectrum and by telluric absorptions of $\mathrm{N}_{2} \mathrm{O}, \mathrm{O}_{3}, \mathrm{H}_{2} \mathrm{O}$ and $\mathrm{CO}_{2}$ were accounted for. The sole $\mathrm{CO}$ a priori profile and associated statistics used for all retrievals have been constructed using averaged volume mixing ratio (vmr) from the WACCM model (the Whole Atmosphere Community Climate Model; http://waccm.acd.ucar.edu) and from ACE-FTS occultation measurements (version 2.2 of the Atmospheric Chemistry Experiment Fourier Transform Spectrometer; see Clerbaux et al., 2008), in the $15.4-100 \mathrm{~km}$ and $6.5-15.4 \mathrm{~km}$ altitude ranges, respectively. This profile was extrapolated further down and set to $137 \mathrm{ppb}$ for the first layer, considering the slope shown by the ACE-FTS averaged profile in the mid troposphere. Pressure and temperature data are taken from the National Center for Environmental Prediction (NCEP). The CO concentrations are retrieved in 39 layers from the ground $(3.58 \mathrm{~km})$ up to $100 \mathrm{~km}$. The first retrieval layer extends from 3.58 to $4.23 \mathrm{~km}$, the following tropospheric layers go up to $4.91,5.63,6.39,7.18,8.01,8.88,9.78,10.72$ and $11.7 \mathrm{~km}$, the latter being close to the mean tropopause height above Jungfraujoch ( $11.3 \mathrm{~km}$ over the last decade). The retrieved profiles are characterized by the so-called averaging kernels, as described by Rodgers (1990, 2000). The retrieved volume mixing ratio profile $x_{\mathrm{r}}$ is thus related to the true profile $x$ and to the a priori profile $x_{\mathrm{a}}$ by

$x_{\mathrm{r}}=x_{\mathrm{a}}+\mathbf{A}\left(x-x_{\mathrm{a}}\right)+($ errors $)$

in which $\mathbf{A}$ is the matrix whose rows are the averaging kernels. Equation (1) shows that for each layer, the retrieved vmr is a weighted mean of the vmr values at all altitudes, with weights given by the corresponding averaging kernel elements. In the ideal case, the averaging kernels are deltafunctions ( $\mathbf{A}$ is the unit matrix). In reality they are bellshaped functions since no layer can be truly independent from its neighbours. The amplitudes of these functions give an indication of the sensitivity of the retrieval to the true profile in each layer, and their widths of the vertical resolution for that layer. The trace of the averaging kernel matrix A gives the Degrees Of Freedom for Signal (DOFS). On average the retrievals contain 2.23 DOFS for CO. Thus the signal can be separated into two independent layers. To obtain a layer with at least one degree of freedom the first 5 layers need to be combined (from 3.58 till $7.18 \mathrm{~km}$ ), as confirmed by the analysis of the eigenvectors and eigenvalues which are similar to those in Fig. 2 of Barret et al. (2003). While independent, the combined $3.58-7.18 \mathrm{~km}$ layer, harbours still, as per Eq. (1), information from the a priori, nor is this layer free from the influence of $\mathrm{CO}$ variability above this combined layer. The second eigenvalue is equal on average to 0.92 , indicating that $8 \%$ from the information retrieved in this layer is conveyed by the a priori. Regular $\mathrm{HBr}$ Cell measurements are performed and analyzed with linefit v9 (Hase et al., 1999) to characterize the instrumental function of the Bruker IFS-120HR instrument, nor is there any indication of

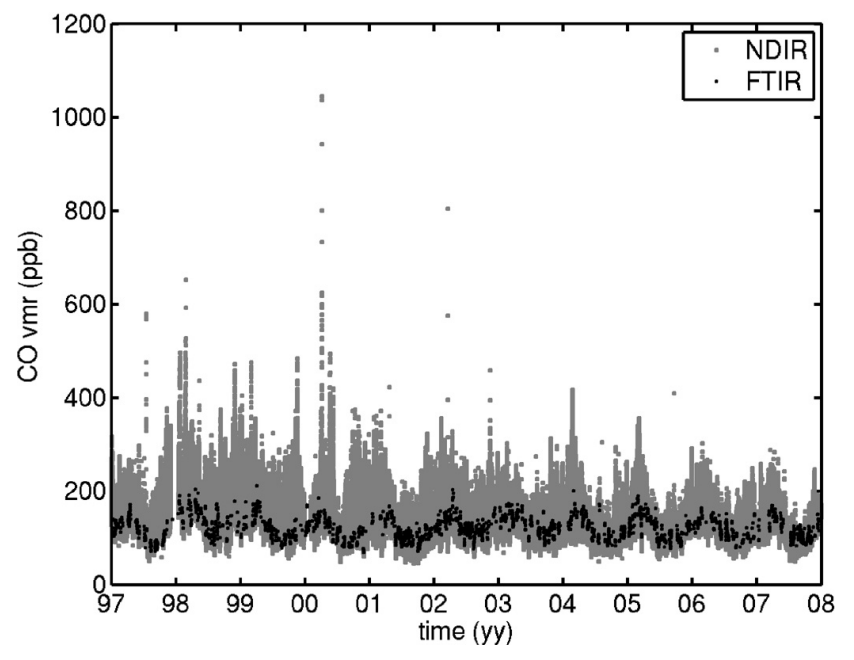

Fig. 1. CO concentrations (in ppb) as a function of time (year). All individual NDIR (grey) and FTIR data (black) prior to any selection/correction criteria.

quality change (such as a shift or drop in the observed DOFS) over time.

The FTIR retrieval data used by Barret et al. (2003), used slightly different input parameters (spectroscopic parameters from HITRAN2000, an a priori profile identical to the one used in the MOPITT version 3 retrieval (Deeter et al., 2003)) and vertical resolution (29 layers between 3.58 and $100 \mathrm{~km}$ ). They also used a smaller 3.58-6.5 km layer in their comparison study. This has of course the advantage, when comparing with in situ measurements, that the difference in sampled airmass is smaller. However since we would like to minimize the impact of the averaging kernel on the long-term trend evolution we deemed a 3.58-7.18 layer more suited for our purposes.

\section{Data and data treatment}

\subsection{Raw datasets}

It is obvious in Fig. 1 (showing the original data prior to any manipulation) that the NDIR dataset exhibits far larger peak values (especially prior to 2003) than the FTIR measurements. This can be attributed to the larger integrated air mass sampled by the FTIR instrument (and thus vertical and horizontal averaging). The FTIR data are less sensitive to "local" events such as thermally-induced vertical transport of CO from the valleys (Henne et al., 2004). Also clear sky conditions are needed to perform the FTIR measurements whereas 2 to $6 \%$ of NDIR CO measurements are associated with (cloudy) South Föhn events (Zellweger et al., 2003). Such events are capable of transporting polluted air masses from the highly industrialized Po Basin in Northern Italy to the Jungfraujoch (Reimann et al., 2008). Indeed, in 
situ CO concentrations at JFJ are on average highest during south-easterly advection (Gilge et al., 2010). Other meteorological situations associated with elevated $\mathrm{CO}$, are synoptic lifting and thermally-induced vertical transport (Zellweger et al., 2003).

The second striking feature is the different temporal evolution of the FTIR and NDIR datasets. While the overall $\mathrm{CO}$ trend of the FTIR data is only slightly negative $\left(-0.8 \pm 0.4\right.$ ppb year $\left.^{-1}\right)$, the NDIR data exhibit a far stronger negative trend $\left(-3.21 \pm 0.03\right.$ ppb year $\left.^{-1}\right)$. The trends were obtained by a simple robust linear fit, using bisquare weights. The uncertainty on the slope corresponds to the $2 \sigma$ standard error. The trend for the in situ measurements agrees well with the observed CO trend at the Zugspitze summit (2962 m a.s.l. in the German Alps) of $-3.16 \pm 0.4$ ppb year $^{-1}$ for the 1995 to 2002 period (Gilge et al., 2010). Next we will explore possible reasons for the trend difference observed at JFJ.

\subsection{Humidity correction}

Since the NDIR instrument removes $\mathrm{H}_{2} \mathrm{O}$ prior to the detection of $\mathrm{CO}$, it effectively measures the dry air volume mixing ratios. FTIR does not and thus measures moist air vmrs. Using meteorological data, in casu relative humidity $(\mathrm{RH})$, temperature $(T)$ and total pressure ( $p_{\text {moist }}$ ), from MeteoSwiss, we have converted the dry air NDIR measurements to moist air volume mixing ratios by using the following approach:

We can derive the partial pressure of $\mathrm{H}_{2} \mathrm{O}\left(p_{\mathrm{H}_{2} \mathrm{O}}\right)$ from the relative humidity and temperature using:

$\mathrm{RH}=\frac{p_{\mathrm{H}_{2} \mathrm{O}}}{p_{\mathrm{H}_{2} \mathrm{O}, \mathrm{sat}}} \times 100 \%$

And the saturated water vapour pressure above water as given by:

$p_{\mathrm{H}_{2} \mathrm{O}, \mathrm{sat}}=6.112 \exp \left(\frac{17.62 T}{(243.12+T)}\right)$

( $T$ in ${ }^{\circ} \mathrm{C}, p$ in hPa, taken from the guide to Meteorological Instruments and Methods of Observation (CIMO Guide) (World Meteorological Organisation, 2008)).

Then the ratio of moist air $\mathrm{CO}$ vmr over dry air $\mathrm{CO}$ vmr is given by

$$
\frac{\mathrm{CO}_{\text {moist }}}{\mathrm{CO}_{\text {dry }}}=\frac{\left(p_{\text {moist }}-p_{\mathrm{H}_{2} \mathrm{O}}\right) / M_{\text {dry air }}}{\left(\left(p_{\text {moist }}-p_{\mathrm{H}_{2} \mathrm{O}}\right) / M_{\text {dry air }}+p_{\mathrm{H}_{2} \mathrm{O}} / M_{\mathrm{H}_{2} \mathrm{O}}\right)}
$$

with

$M_{\text {dry air }}=28.96 \mathrm{~g} \mathrm{~mol}^{-1} \quad$ and $\quad M_{\mathrm{H}_{2} \mathrm{O}}=18.015 \mathrm{~g} \mathrm{~mol}^{-1}$

The correction factor ranges between 0.978 and 0.9998 , with a mean value of 0.993 . The impact on the slope and general appearance of the dataset is negligible, with the NDIR trend for moist air volume mixing ratio equal to $-3.20 \pm$ 0.03 ppb year $^{-1}$. Note that this correction does not take into account the variability of the humidity as a function of altitude. However, given the negligible impact of the implemented correction on the overall trend, we can safely state that a further correction or inversely, the conversion of the FTIR data into dry air columns would not explain the observed trend differences.

\subsection{Selection of data representative of free troposphere air}

It is obvious that there is a substantial difference between both techniques with regard to the actual air sampled. As mentioned in Sect. 2, NDIR essentially samples the CO concentration in the surface air at the Jungfraujoch site. The FTIR instrument, on the other hand, samples the CO content in the air along a slant column between the station and the sun. Pressure broadening of the spectroscopic lines allows the retrieval of a $\mathrm{CO}$ vertical distribution although it is characterized by a low vertical resolution. Therefore, the 3.58$7.18 \mathrm{~km}$ layer airmass used here is far larger than the in situ sampled airmass. Also note that at high solar zenith angles the horizontal extent above the Jungfraujoch reaches up to $20 \mathrm{~km}$.

While air measured in situ at the Jungfraujoch site can mostly be regarded as representative of the free troposphere, given the site's altitude, influence from the boundary layer cannot be completely discarded. While the convective boundary layer (CBL) above the Alps might not reach the station altitude it is not necessarily identical with the mixing height of surface pollutants (De Wekker et al., 2004). A so called injection (or aerosol) layer can form above the CBL top which intermittently receives CBL air (Henne et al., 2004). It has been shown from airborne Lidar observations (Nyeki et al., 2000) and model studies (De Wekker et al., 2004) that JFJ can be situated well within the injection layer during summer, day-time, fair-weather conditions. It is clear from Fig. 1, that the NDIR data are often influenced by high $\mathrm{CO}$ events, probably associated with atmospheric boundary layer (ABL) air reaching the Jungfraujoch observatory. As mentioned above, regional pollution from the Po Basin is likely to be occasionally measured at JFJ during south-easterly advection. Since the European emissions declined significantly during the considered years (see Fig. 13), the negative in situ CO trends at JFJ are indeed more pronounced for south-easterly $\left(-2.0 \%\right.$ year $\left.^{-1}\right)$ than for northwesterly advection $\left(-1.6 \%\right.$ year $\left.^{-1}\right)$ (Gilge et al., 2010).

It is therefore crucial to somehow filter out these events, separating the background free tropospheric measurements from the disturbed ones (Zellweger et al., 2003). There are several methods to perform this filtering. One is to analyze and take into account various meteorological parameters (Forrer et al., 2000; Zellweger et al., 2003). Other methods use the determination of air mass origin (Derwent et al., 1998) or statistical filtering techniques such as the one described by Novelli et al. (1998); O'Doherty et al. (2001); or Ruckstuhl et al. (2010). 
Statistical methods do not require auxiliary data, but exist in several forms and shapes. The one used in this article is the one developed by Ruckstuhl et al. (2010). In this so-called REBS technique (Robust Extraction of Background Signal), like in other statistical techniques, one tries to identify measurements that deviate significantly from the best fit to the dataset. One assumes that background data have a normal distribution around this fit. Typically a polynomial function is fitted through the data after which only the negative residual values are used to determine the shape of the normal distribution (Novelli et al., 1998; O'Doherty et al., 2001). REBS differs from the above in that it does not fit a polynomial, but uses robust local regression (Cleveland, 1979) to determine the optimal fit. This implies that no a priori assumptions on the shape of the fit are made. A bandwidth of 3 months is used such that the majority of the data falling within this band is likely to have a normal distribution (a prerequisite for the technique to work properly) while at the same time an appropriate mapping of the seasonality is still feasible.

Note that the technique does not offer a disturbed/background flag for each individual measurement. Instead it calculates a smooth curve fit, representative for the background free troposphere signal. Background air is thus defined as those measurements which fall within the Gaussian distribution around this curve fit. By the way it is calculated, the negative NDIR-REBS fit residuals are well represented by this Gaussian fit, but it is harder to draw a line for the positive residuals. One could define that all data with residuals that exceed $3 \sigma$ are polluted as per Ruckstuhl et al. (2010), but this leaves a significant number of disturbed measurements that fall below this $3 \sigma$ threshold, which in turn results in an overrepresentation of data points with a positive residual towards the REBS curve fit.

Therefore we calculate the residuals towards the REBS robust curve fit and plot a histogram of these residuals using $1 \mathrm{ppb}$ size bins. A Gaussian curve is fitted through the histogram using only the negative residuals (which are mirrored onto the positive side to obtain a true Gaussian shape). For all data points that have a residual larger than $1 \sigma$, as determined from the Gaussian fit, the following method is applied. For each individual histogram bin, the difference between the total number of data points and the Gaussian histogram fit, determines the number of data that need to be rejected. For each point within the bin, the summed NDIRREBS fit residual of its 2 neighbouring (in time) data points, was calculated. Data points which are taken shortly before or after measurements which have a high excess $\mathrm{CO}$ value (and are thus probably disturbed by boundary air), are more likely affected themselves. All data within the bin are ranked according to this combined neighbour residual (CNR) and those with the highest CNR are primarily rejected until the number of data points to be rejected is reached. $12.5 \%$ of the NDIR data is thus removed from the dataset with the REBSCNR routine.

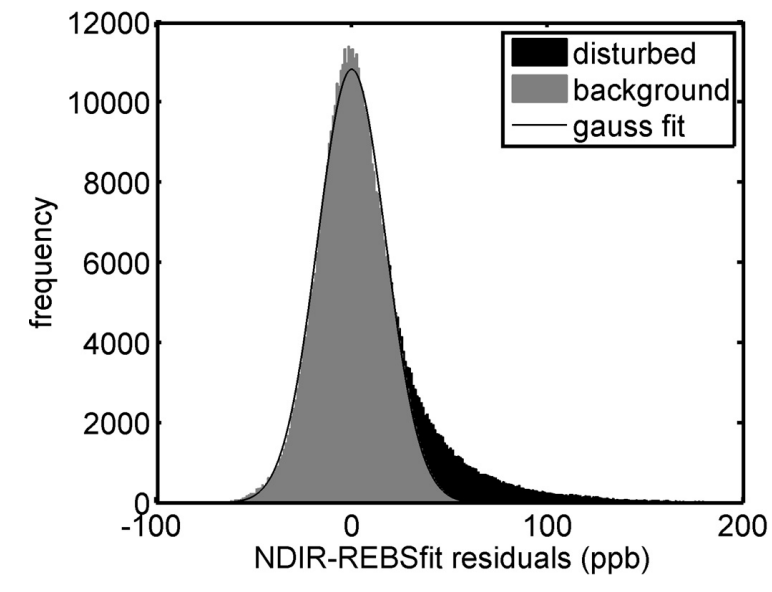

Fig. 2. Histograms of filtered (grey) and rejected (black) NDIRREBS residuals data using REBS filtering.

A histogram of the whole NDIR dataset and the background data is shown in Fig. 2. Using a robust linear fit we calculate a slope of $-2.62 \pm 0.03$ ppb year $^{-1}$ of the REBSCNR filtered free troposphere dataset. Also note that the slope is somewhat lower than one would obtain by fitting the REBS curve fit itself or by using purely random selection criteria on the entire gauss curve, instead of the CNR method, namely $-2.66 \mathrm{ppb}$ year $^{-1}$. In any case it is clear that the derived slope depends somewhat upon the selection method used and that the actual uncertainty on the trend exceeds the reported $2 \sigma$ standard error. For instance, a completely different more crude filtering method in which we merely take the lowest $68 \%$ of the CO data points for autumn (September to November) and winter (December till February) or $40 \%$ for the spring-summer seasons, as based on Zellweger et al. (2003), yields an overall NDIR CO trend of $-2.74 \pm 0.03 \mathrm{ppb}$ year $^{-1}$. But even taking an enlarged uncertainty into account, the FTIR and NDIR trends remain significantly different.

While the FTIR data are far less affected by local pollution, a similar filtering mechanism (but using 2 ppb bin widths to obtain a more regular Gaussian histogram shape) was applied for consistency's sake. The resulting residual histogram is shown in Fig. 4. The FTIR residual data hardly show a distinct tail. Still $9.4 \%$ of the data was filtered out. The obtained histogram also shows a smaller standard deviation (12 ppb) than the NDIR data (17 ppb), which is probably due to the larger integrated airmass sampled.

While the filtering has a significant impact on the NDIR timeseries (see Fig. 3), its overall trend changing from -3.20 to $-2.62 \pm 0.03$ ppb year $^{-1}$, its impact on the FTIR timeseries is minimal as can be seen in Fig. 5 (trend changing from -0.8 to $-0.7 \pm 0.3$ ppb year $^{-1}$ ). The difference between FTIR and NDIR trend remains substantial and can therefore not be explained by the impact of boundary layer influence alone. 


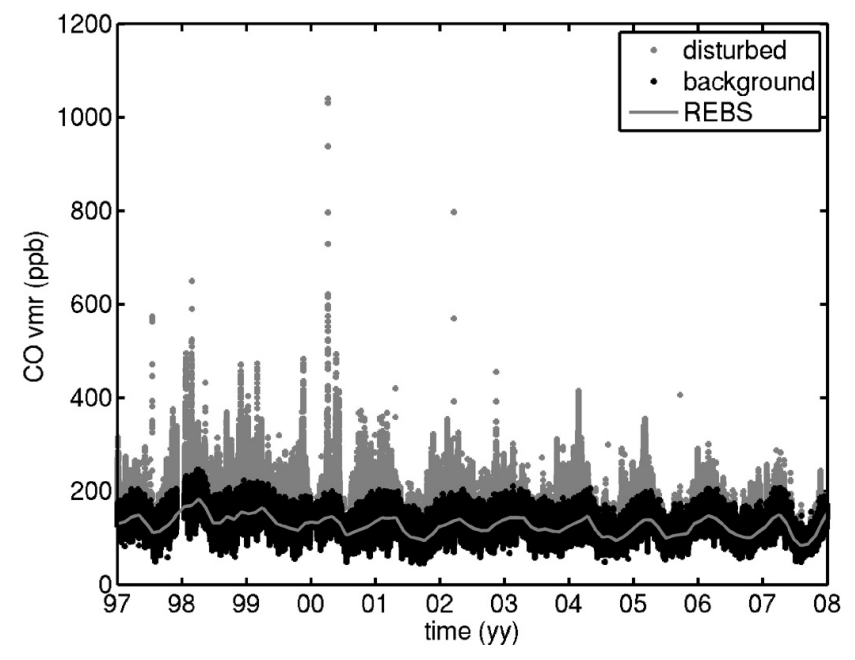

Fig. 3. Time series of NDIR CO concentrations (in ppb) at Jungfraujoch: the complete dataset before filtering (grey) and the dataset after REBS-CNR filtering (black; the grey curve is the REBS-CNR fit).

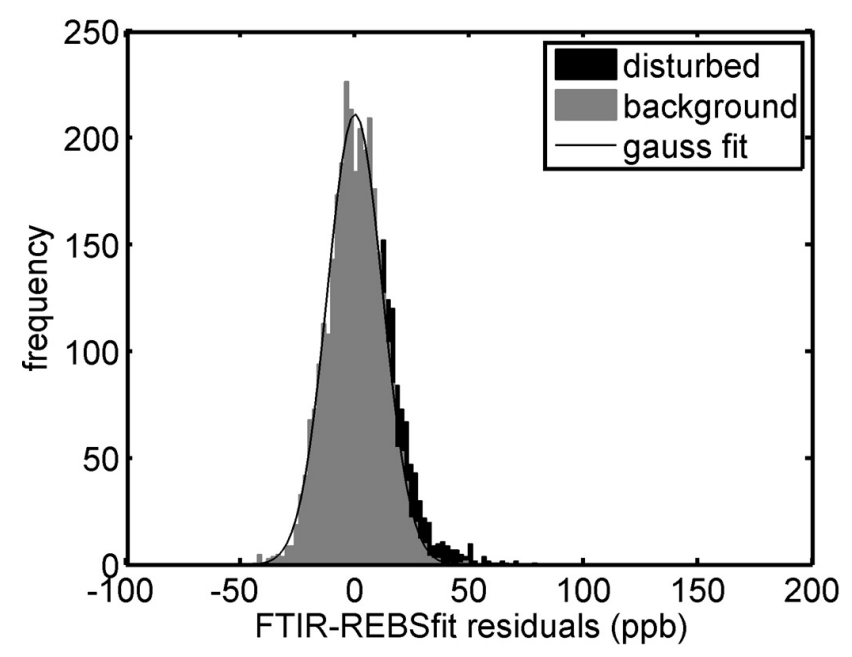

Fig. 4. Histogram of filtered background (grey) and rejected disturbed (black) FTIR-REBS residual data using REBS-CNR filtering.

\subsection{Temporal overlap issues}

NDIR measurements are taken $24 \mathrm{~h}$ a day, regardless of meteorological conditions. FTIR measurements however are only possible during daytime and they require strict cloudfree conditions. Therefore we looked at NDIR and FTIR data which have been taken in close temporal $( \pm 10 \mathrm{~min})$ proximity of each other.

We also wanted to look at the correlation between the overlapping NDIR and FTIR data. For each individual FTIR measurement, a corresponding NDIR data point was constructed by taking the average of all NDIR measurements within a
Table 1. NDIR and FTIR CO trend in $\mathrm{ppb}$ year $^{-1}$ and number of data points (\#) for the original raw data (Orginal), after humidity correction (Hum corrected), after humidity correction and REBSCNR filtering (REBS-CNR) and after all the above and using either $\pm 10 \mathrm{~min}, \pm 3 \mathrm{~h}$ or \pm 2 day overlap times.

\begin{tabular}{lcccc}
\hline & NDIR trend & NDIR \# & FTIR trend & FTIR \# \\
\hline Original & $-3.21 \pm 0.03$ & 538789 & $-0.8 \pm 0.4$ & 2687 \\
Hum corrected & $-3.20 \pm 0.03$ & 538789 & $-0.8 \pm 0.4$ & 2687 \\
REBS-CNR & $-2.62 \pm 0.03$ & 471365 & $-0.7 \pm 0.3$ & 2456 \\
10 min & $-2.7 \pm 0.3$ & 2273 & $-0.8 \pm 0.3$ & 2273 \\
3 h & $-2.7 \pm 0.3$ & 2372 & $-0.7 \pm 0.3$ & 2372 \\
2 day & $-2.7 \pm 0.3$ & 2427 & $-0.7 \pm 0.3$ & 2427 \\
\hline
\end{tabular}

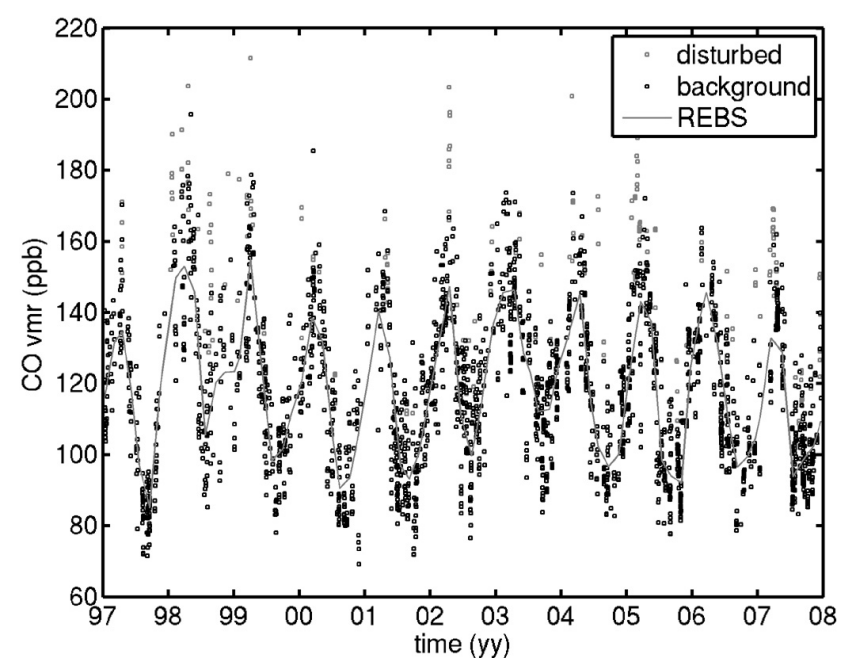

Fig. 5. Time series of FTIR CO concentrations (in ppb) at Jungfraujoch. Background data determined by REBS-CNR filtering are shown in black. The curve of the REBS-CNR fit is shown in grey.

certain overlap time of the FTIR measurement. Note that an individual FTIR measurement takes on average approximately $10 \mathrm{~min}$. We also wanted to explore how wide this overlap time needed to be taken to obtain the best correlation. Therefore we varied the temporal overlap width between $\pm 10 \mathrm{~min}$ and $\pm 1000 \mathrm{~h}$, again averaging all NDIR data that fall within the temporal overlap bounds of each FTIR measurement.

The correlation coefficient $(R)$ reaches a maximum of 0.76 when averaging the NDIR data within $30 \mathrm{~h}$ of each FTIR measurement. Only after the overlap time increases over $\pm 60 \mathrm{~h}$, does the correlation start to decline again. Given that the large correlation is probably largely due to the seasonal cycle (hence the large $30 \mathrm{~h}$ integration time), we also wanted to verify if there is a significant correlation between FTIR and NDIR CO on even shorter timescales. Therefore we also looked at the correlation between the NDIR and 


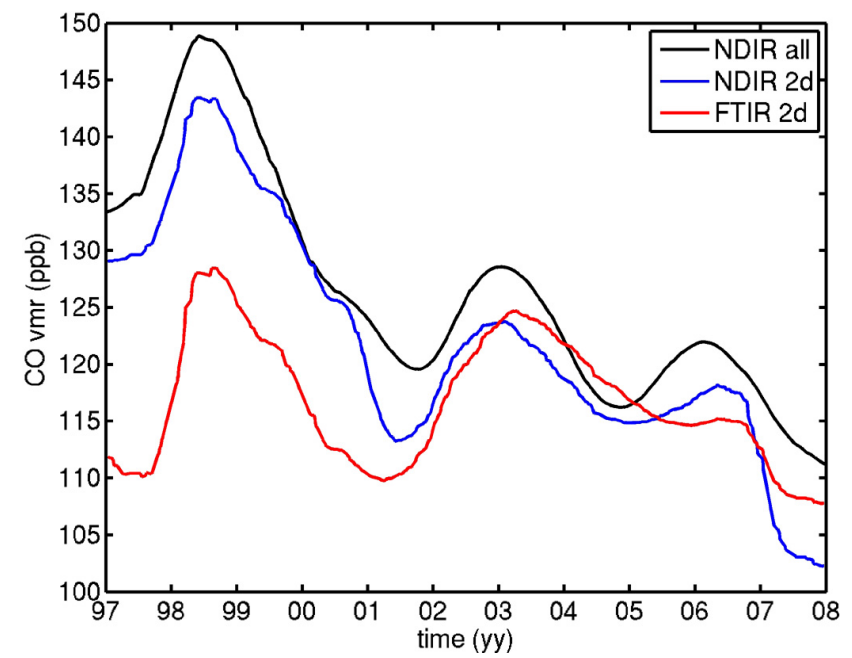

Fig. 6. Time series of NDIR (black and blue curves) and FTIR (red curve) data for $\mathrm{CO}$ vmr smoothed with $\mathrm{KZ}(365,3)$. For the black curve, all NDIR data were considered; for the blue curve, NDIR data were selected according to a temporal overlap criterium with the FTIR data of \pm 2 days.

FTIR CO-REBS fit residuals. This removes the seasonal and long-term variability from the dataset. The correlation is far weaker for the residual values $(0.48)$ and reaches a maximum between \pm 3 and $\pm 8 \mathrm{~h}$ overlap time. These results show that the correlation between NDIR and FTIR is significant even with regard to short-term CO fluctuations. However, as with the REBS-CNR filtering routine, the choice of temporal collocation criteria does not have a significant impact on the NDIR and FTIR trend. Table 1 lists all the linear robust fit results for the original raw data, after humidity correction, after REBS-CNR filtering and using $\pm 10 \mathrm{~min}, \pm 2$ days and $\pm 3 \mathrm{~h}$ overlap times.

All the above indicates that both NDIR and FTIR are to a large degree influenced by the same CO fluctuations, yielding significantly high correlation coefficients, but at the same time are sufficiently diverse for such significant discrepancies in trends to arise.

\subsection{Kolmogorov-Zurbenko filtered data}

Given that a simple linear fit is rather simplistic as a trend marker, a Kolmogorov-Zurbenko filter (or KZ filters in short) (Zurbenko, 1986) was applied to the original REBS filtered and 2-day overlapping NDIR-FTIR datasets. The $\mathrm{KZ}(m, k)$ filter is a low pass filter described by $\mathrm{k}$ repetitions of a moving average of $m$ data points ( $-i$ to $i$ ), which smoothes the time series to a selected cut-off frequency:

$Y_{k}=\frac{1}{m} \sum_{j=-i}^{i} X_{k, j}$

The resulting time series becomes the input data for the second pass and so on until the number of passes is equal to

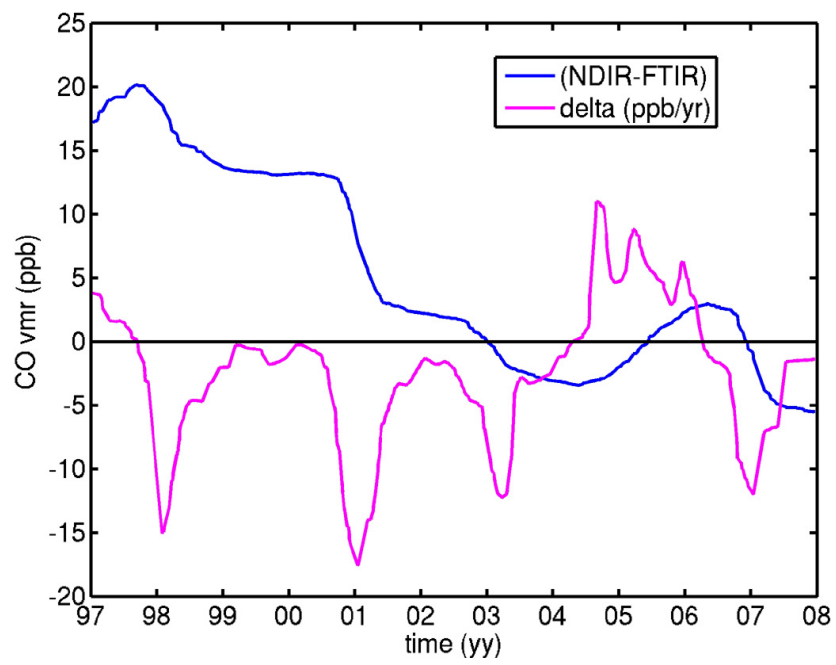

Fig. 7. Blue curve: Time series of the difference between NDIR and FTIR data. NDIR data have been defined according to a temporal overlap criterium with the FTIR data of \pm 2 days. Magneta curve: KZ(74,5) smoothed gradient of the NDIR-FTIR difference as a function of time.

$k$. The benefit of this filter technique is that it is capable of averaging over sections of missing data without the need for restoration. Selected cut-off frequencies are defined by the $m$ and $k$ values of the moving average. The characteristic filter values that achieve the cut-off frequencies can be used to interpret an effective filter width $\left(N_{\text {eff }}\right)$ :

$N_{\text {eff }}=m \cdot k^{1 / 2}$

This width defines the effective separation value between frequencies allowed to pass through the filter and those that are not. Imposing separation at several frequencies, allows for separation of multiple timescales.

Here we have applied a $m=365$ days or 12 months and $k=3$ filter $\left(N_{\text {eff }}=1.7\right.$ years $)$, typically noted as $\operatorname{KZ}(365,3)$, to determine the long-term trend. Likewise the $\operatorname{KZ}(74,5)$ combination is often used to determine the seasonal pattern. Figure 6 shows the time series of the KZ filtered NDIR data and the 2 day overlapping NDIR and FTIR data. The NDIR signal clearly shows three distinct episodes of $\mathrm{CO}$ increases. The first 1998 peak is attributed to an increase of biomass burning emission on a global scale (Simmonds et al., 2005). 2003 featured extremely high Central European summer temperatures and accompanying forest fires in Portugal which could explain the observed increase, either directly or via increased vertical upward transport (Luterbacher et al., 2004; Tressol et al., 2008; Yurganov et al., 2004, 2005). According to van der Werf et al. (2010), also 2005-2006 did not feature any increase of $\mathrm{CO}$ emissions on a global scale; however regional fires could be substantial. Fires in Mexico and Central America for instance were particularly intense during this period (as they were in 2003) (see GFEDv3 database, van der Werf et al., 2010). 

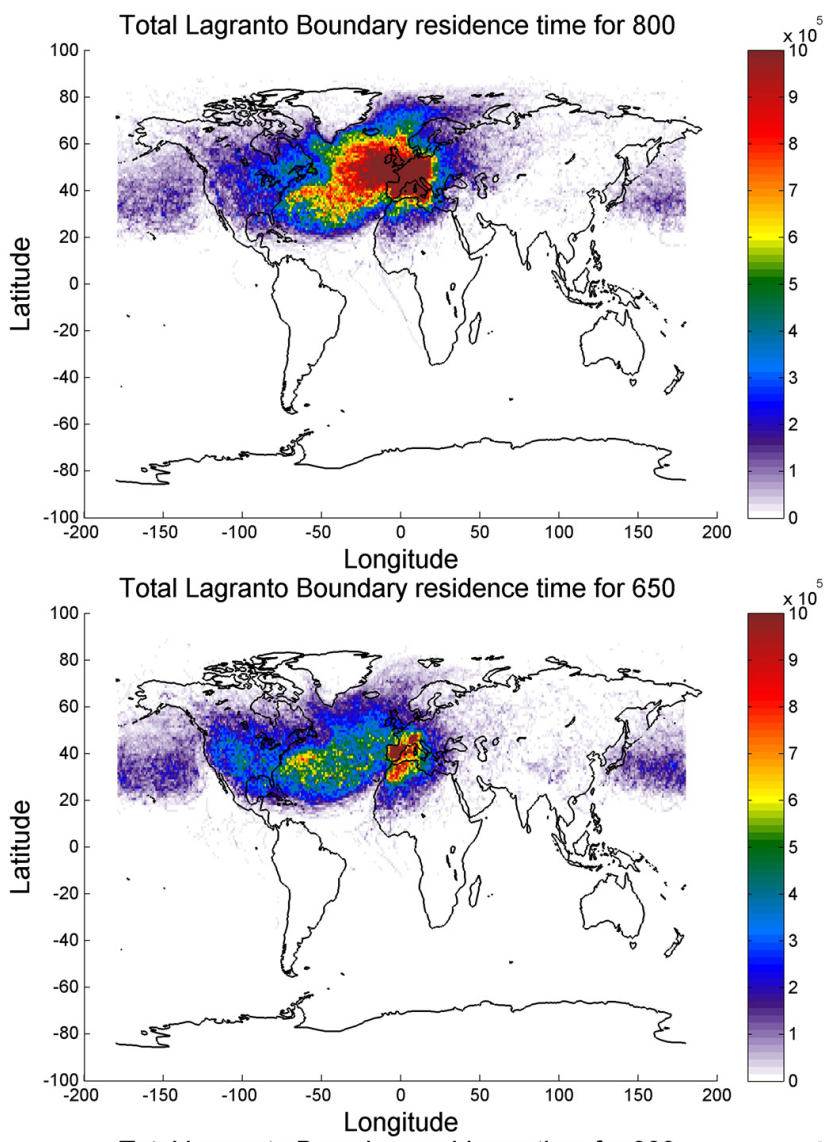

Total Lagranto Boundary residence time for 300

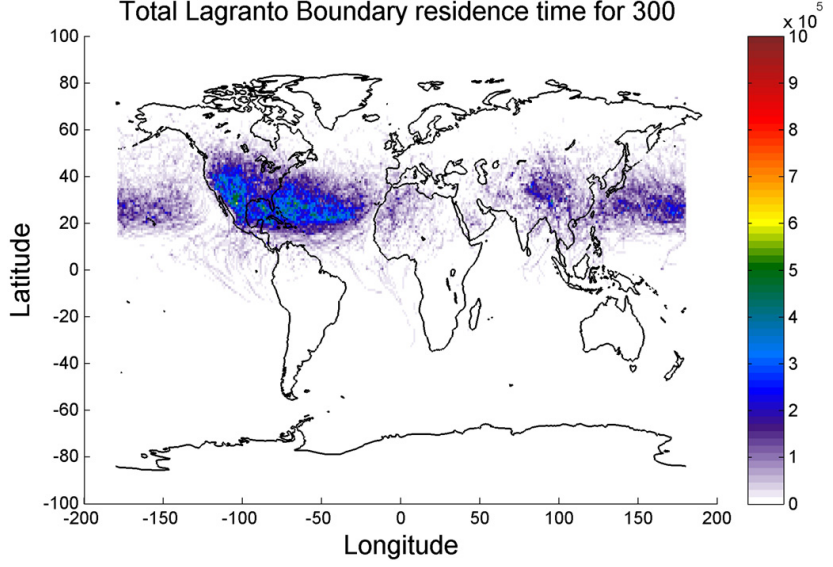

Fig. 8. Total boundary residence time (in seconds) for air masses arriving at Jungfraujoch at 800 (top), 650 (middle) and $300 \mathrm{hPa}$ (bottom) averaged over the 1997-2007 period, as simulated by Lagranto. Scale is from 0 to $10 \times 10^{5} \mathrm{~s}(\sim 12$ days $)$.

All these features are also present in the FTIR data, although the 2006 peak is much less prominent. This lower FTIR sensitivity to the 2005-2006 episode, also causes the only strong reversal in the overall negative NDIR-FTIR difference gradient (see Fig. 7). The strongest contrast with NDIR observations is that after each increased episode the FTIR data return to the same $\sim 110$ ppb base value (see
Fig. 6). In case of the NDIR time series, the minima in the inter-annual trend line are consistently getting lower. If we look at the NDIR-FTIR difference (Fig. 7), we see an almost stepwise pattern and indeed if we plot this trend line as well as its gradient (smoothed with the $\mathrm{KZ}(74,5)$ filter to eliminate short-term noise), we see that between mid 1997 and mid 2004, the trend is almost consistently negative, with strong peak increases in the NDIR-FTIR difference during winter 1997-1998, 2000-2001 and spring 2003. Such stepwise decreases could point to temporary problems with the instrumentation. Here we have to note that these steps are visible in the NDIR-FTIR difference only and do not occur in the individual NDIR or FTIR dataset. Furthermore, it is clear from Sect. 3.1 that the NDIR data are routinely calibrated against a NIST reference and that any perpetuating drift is extremely unlikely, nor is there any indication of quality change in the FTIR dataset (see Sect. 3.2). A more reasonable explanation is that a quasi constant NDIR-FTIR bias shift is periodically influenced by episodes of elevated $\mathrm{CO}$ emissions which have a higher impact on NDIR CO. However, it is also clear that due to the limited number of overlapping NDIR FTIR data the KZ smoothing function might level out otherwise visible features such as the 2004 decrease (see Fig. 6) which is much less prominent in the NDIR $2 \mathrm{~d}$ (using a \pm 2 day temporal overlap window with FTIR, see Sect. 4.4) dataset than in the full NDIR dataset.

\section{Identification of source regions}

In order to account for the different long-term $\mathrm{CO}$ trends in the FTIR and NDIR data we turn our attention to the difference in the vertical airmass sampled and the implied possible difference in the source regions that influence the $\mathrm{CO}$ content in both measurement types. Indeed, Zellweger et al. (2009) explained their observed difference between surface in situ CO measurements from several Swiss stations, on the influence of different source regions on each individual station, especially as a function of altitude.

Thus the Lagranto (Wernli and Davies, 1997) Lagrangian trajectory model was used to calculate transport pathways towards the Jungfraujoch site, based on European Centre for Medium-Range Weather Forecasts Re-Analysis (ECMWF ERA) Interim windfields from 1990 to end of 2007. Starting points ranged from 850 to $100 \mathrm{hPa}$. Back trajectories were calculated every $6 \mathrm{~h}$ going 20 days backwards in time. This brings them well beyond the synoptic period and thus individual trajectories can be considered unreliable due to the poor simulation of fronts and convective processes which occur along their path. Using ensembles of trajectories mediates this problem to a certain degree but systematic errors on the long range pathways (especially towards Asia) cannot be completely ruled out. Also the model uses $1 \times 1^{\circ}$ wind fields and thus the orography of the Alps is not optimally represented. The model sets the ground level at Jungfraujoch at 
$1500 \mathrm{~m}(\sim 850 \mathrm{hPa})$ instead of the actual $3580 \mathrm{~m}(\sim 650 \mathrm{hPa})$. Therefore the actual contributions to the JFJ station might contain some sub $650 \mathrm{hPa}$ altitude information as well.

From these trajectories, the time an air mass had spent within the atmospheric boundary layers (ABL) over Europe, North America, Asia, etc. was calculated by comparing the trajectory altitude with boundary layer heights as taken from ERA Interim re-analysis.

It can be seen in Fig. 8 that the CO concentration observed above Jungfraujoch has a different source region depending on the altitude above the surface, in agreement with Pfister et al. (2004), who used the MOZART-2 chemistry transport model to simulate the $\mathrm{CO}$ budget over Europe. The lowest arrival height features a strong influence of Western Central Europe and the Eastern Atlantic, whereas the $650 \mathrm{hPa}$ arrival level covers most parts of the United States, the Atlantic and South-western Europe. For the highest arrival height, the European influence is negligible but the air masses had been in contact with the boundary layer over the Western Atlantic, the United States, the Pacific and Asia.

We did not observe any significant long-term trend in the source regions over the years (not shown), although a year to year variability is present (Cui et al., 2011). Also a seasonal difference was clearly noticeable. Figure 9 shows an Asian influence during winter, while the European influence is strongest during the summer. The seasonality of the North American pathways exhibit a smaller seasonal cycle at low altitudes. At higher altitudes, the European influence becomes ever smaller and North America and Asia become the dominant contributors. The shown uncertainties have been derived by using yearly ensembles of the data. It therefore contains real year to year variability, but also contains a large fraction of actual uncertainty of the ensemble method.

Given this seasonality we calculated the trends using all REBS-CNR filtered NDIR and FTIR data for winter (DJF) and summer (JJA) (not shown). For the NDIR data, we see a difference in the summer and winter trend. While the overall trend was $-2.62 \pm 0.03$ ppb year $^{-1}$ (see Table 1 ), the winter NDIR was only $-1.57 \pm 0.05$ ppb year $^{-1}$ while the summer data was $-2.72 \pm 0.04$ ppb year $^{-1}$. This is in line with what can be expected, if there is an increased impact of growing Asian emissions in winter. The FTIR data on the other hand, having fewer data points and thus substantially larger uncertainty, showed a reverse, but insignif-

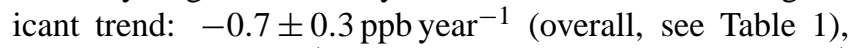
$-0.2 \pm 0.5$ ppb year $^{-1}$ (winter) and $-0.1 \pm 0.4$ ppb year $^{-1}$ (summer).

Single trajectory models such as LAGRANTO are not suited for the quantitative determination of the CO concentrations above Jungfraujoch, as they do not account for dispersion processes. However, using an ensemble of single LAGRANTO trajectories does allow for a qualitative assessment when combined with emission inventories. Combining all calculated trajectories at a certain pressure level gives a good indication of the overall source area. Since
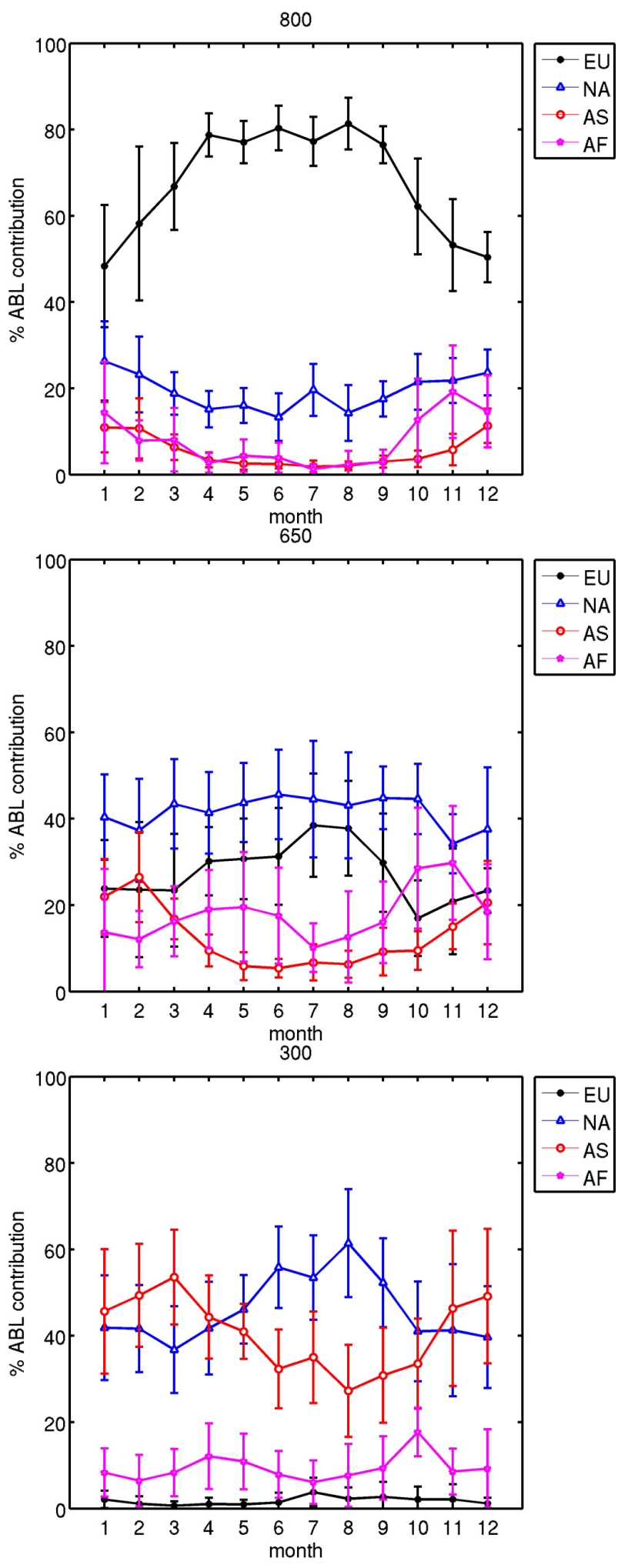

Fig. 9. Average monthly residence time in the Atmospheric Boundary Layer (ABL) per region (EU: Europe, NA: North America, AS: Asia, AF: Africa) relative to the total ABL residence time arriving at Jungfraujoch at 800 (top), 650 (middle) and $300 \mathrm{hPa}$ (bottom plot). The error bars correspond to the $1 \sigma$ standard deviation, derived from analysing the yearly contributions separately. 

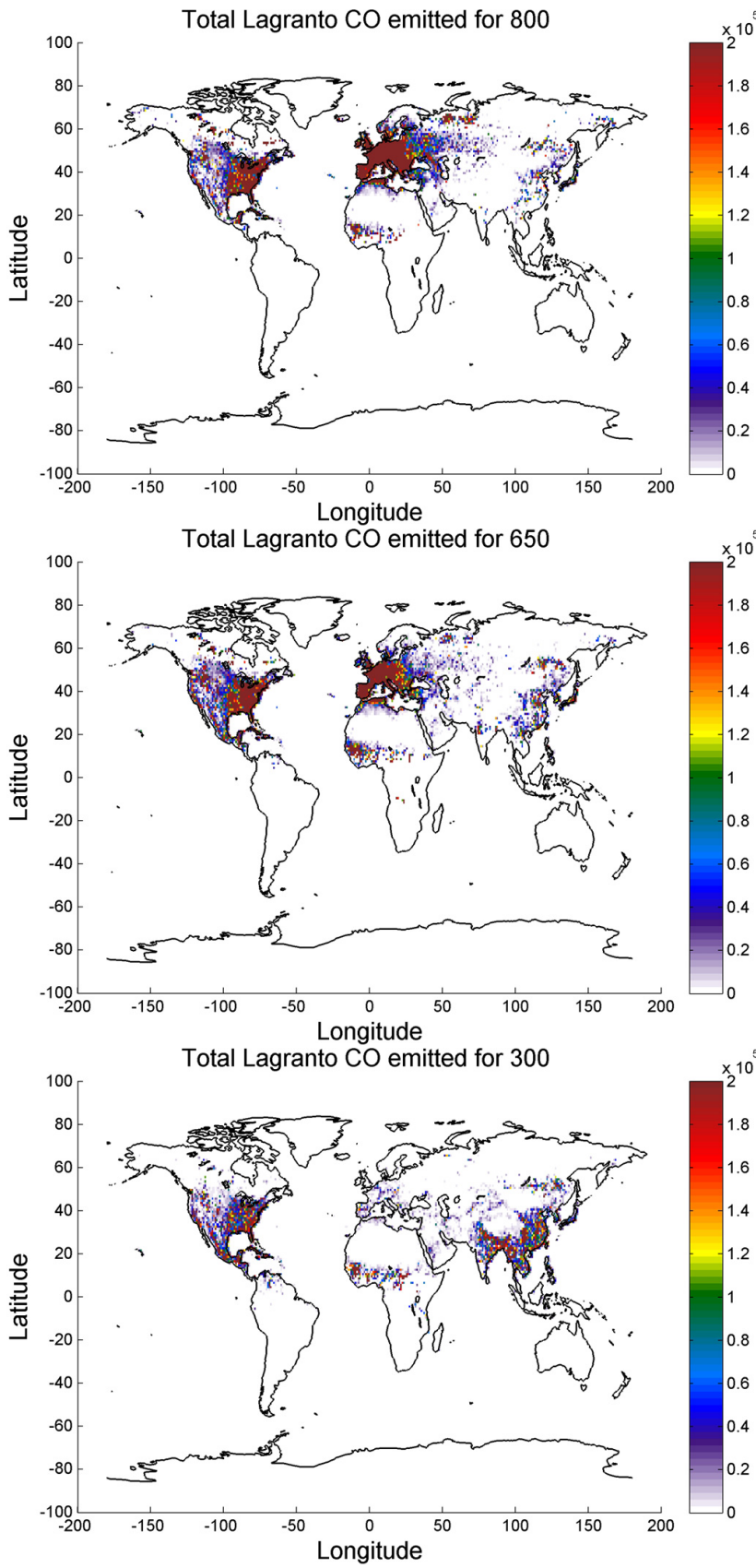

Fig. 10. Total CO emitted and transported towards Jungfraujoch at 800 (top), 650 (middle) and $300 \mathrm{hPa}$ (bottom) for the year 2000, using total 1997-2007 residence times, as simulated by Lagranto and EDGAR v4.1 and GFED v3 emissions. Scale ranges between 0 and $2 \times 10^{5} \mathrm{~kg}$.

we did not see any noticeable trend in this source area distribution over the years, we started with the summed total residence time over the entire 1997-2007 period. This ignores the inter-annual variability in the source regions. Using yearly summed residence times, instead of the entire 19972007 period, yielded ensembles which still showed clear in- dividual trajectories instead of a more uniform source region area. The only inter-annual variability thus might come from changes in emissions. For biomass burning we have used the GFEDv3 CO emissions (van der Werf et al., 2010). For the anthropogenic emissions we used the EDGAR emission database (European Commission, Joint Research Centre (JRC)/Netherlands Environmental Assessment Agency (PBL). Emission Database for Global Atmospheric Research (EDGAR), release version 4.1, http://edgar.jrc.ec.europa.eu, 2009).

The yearly gridded EGDAR data consist of 2000-2005 data only. The 2006 and 2007 data were constructed by extrapolating the 2004-2005 trend. The 1997 till 1999 data were constructed from the linear interpolation of the 1995 (present in the database) and 2000 gridded data. The monthly GFED data was summed to yearly values, to comply with EDGAR.

Multiplying the total residence time (in s) with the emission strength for a given year at each grid box (in $\mathrm{kg} \mathrm{s}^{-1}$ ) yields the mass that gets fed into that grid box and ends up being transported towards the Jungfraujoch at a particular pressure level. In order to account for the different airmass densities at different pressure levels, one needs to convert the emitted $\mathrm{CO}$ mass to mass mixing ratios at the emission source and back again to mass values at the Jungfraujoch site. This was done by using the International Standard Atmosphere (International Organization for Standardization, Standard Atmosphere, ISO 2533:1975, 1975.) air density values (thus air mass density variability in time and emission source location is not taken into account, nor is the variability of the boundary layer height, which is arbitrarily set to $1 \mathrm{~m}$ ).

For the REBS-CNR filtered NDIR dataset we looked at the $650 \mathrm{hPa}$ level which more or less corresponds to the Jungfraujoch station altitude. To map the above discussed LAGRANTO output (Lg), shown in Fig. 10, which (given the use of the constructed ensemble residence time output) is in arbitrary $\mathrm{kg}$ units but proportional to the $\mathrm{CO}$ vmr values, onto the NDIR data, one needs to find the corresponding factor $f$ for which

$f \times \mathrm{Lg}=\mathrm{CO}$

With $\mathrm{Lg}$ in $\mathrm{kg}, \mathrm{CO}$ in ppb and $f$ in $\mathrm{ppb} \mathrm{kg}^{-1}$.

Since the LAGRANTO run and emissions do not take any (photo)chemical production (and removal) of $\mathrm{CO}$ into account, these background contributions should be taken into account into the equation, thus

$(f \times \mathrm{Lg})+\mathrm{CO}_{\text {background }}=\mathrm{CO}_{\text {observed }}$

While the background CO level is unknown, by assuming that it is constant over time, $f$ can still be determined by fitting Eq. (8). The optimal conversion factor $f$ turned out to be $(7.3 \pm 1.4) \times 10^{-8}\left(\mathrm{ppb} \mathrm{kg}^{-1}\right)$, while the background $\mathrm{CO}$ value equalled $46.6 \pm 15 \mathrm{ppb}$. This is in line with the contribution to the total CO signal of $35-48 \mathrm{ppb}$ due to the oxidation of $\mathrm{CH}_{4}$ and non-methane hydrocarbons as reported by 


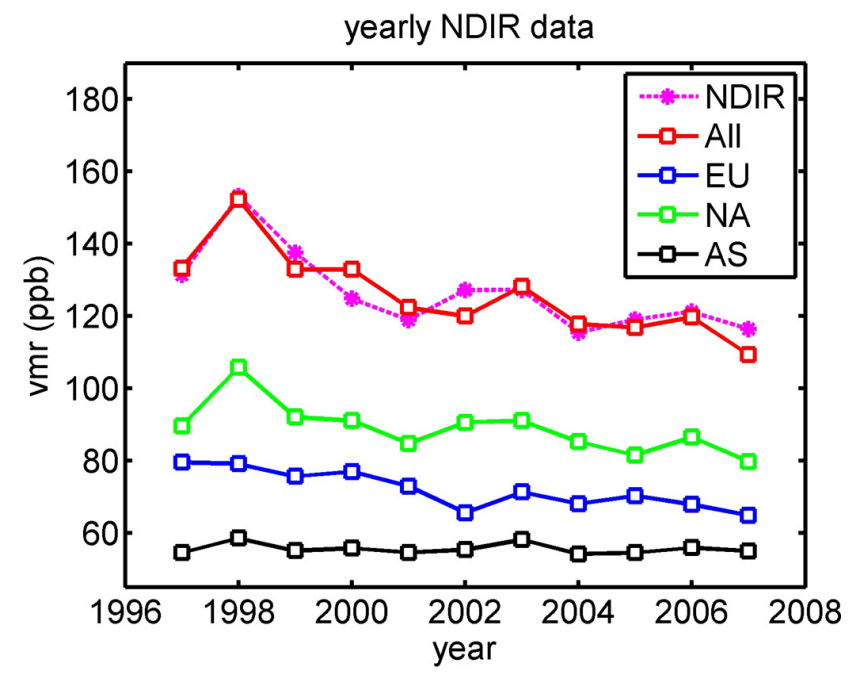

Fig. 11. Yearly mean ground-based in situ CO data (NDIR) as well as model simulated CO mixing ratios above the Jungfraujoch. All, corresponds to the global model simulations, while EU, NA and AS are the model contributions from Europe, North America and Asia, respectively. The fitted $46.6 \mathrm{ppb}$ background has been added to all model output (also the regional ones).

Zellweger et al. (2009). The yearly mean measured and modelled (using the $7.3 \times 10^{-8} \cdot \mathrm{Lg}+46.6 \mathrm{ppb}$ formula) NDIR CO evolution is plotted in Fig. 11.

For the REBS-CNR filtered FTIR remote sensing dataset, we need to combine the modelled output from several pressure levels, taking into account the averaging kernel information (see Eq. 1). The latter is important as the FTIR data still contain some a priori information, which remains constant over time (as discussed in Sect. 3.2). This contribution dampens any potential FTIR trend and therefore this effect needs to be equally applied to the model data. Since we only have a qualitative idea of the real partial column information we've built the "real" partial column $(x)$ from the apriori $\left(x_{\mathrm{a}}\right)$, corrected by the LAGRANTO CO mass mixing ratio (in $\mathrm{kg} \mathrm{kg}^{-1}$ air but holding no quantitative information) towards 1997 as in

$x(\mathrm{yr})=x_{\mathrm{a}} \cdot \operatorname{Lg}(\mathrm{yr}) / \operatorname{Lg}(1997)$.

The LAGRANTO CO mass mixing ratios needed to be mapped onto the FTIR vertical retrieval grid first (this is also the reason we did not use absolute mass values as these depend on grid size). The averaging kernel smoothing is then applied (as per Eq. 1) onto the thus obtained partial column $x$, resulting in the observed partial column $x_{\mathrm{r}}$. Merging the bottom 5 layers of $x_{\mathrm{r}}$, yields our model generated $3.58-7.18 \mathrm{~km}$ layer.

Here, using the same routine as with the NDIR data (fitting Eq. 8), yields an optimal background signal of $43 \pm 17 \mathrm{ppb}$. This is similar to the one found for NDIR. Figure 12 also reveals the declining impact of European emissions and a slight

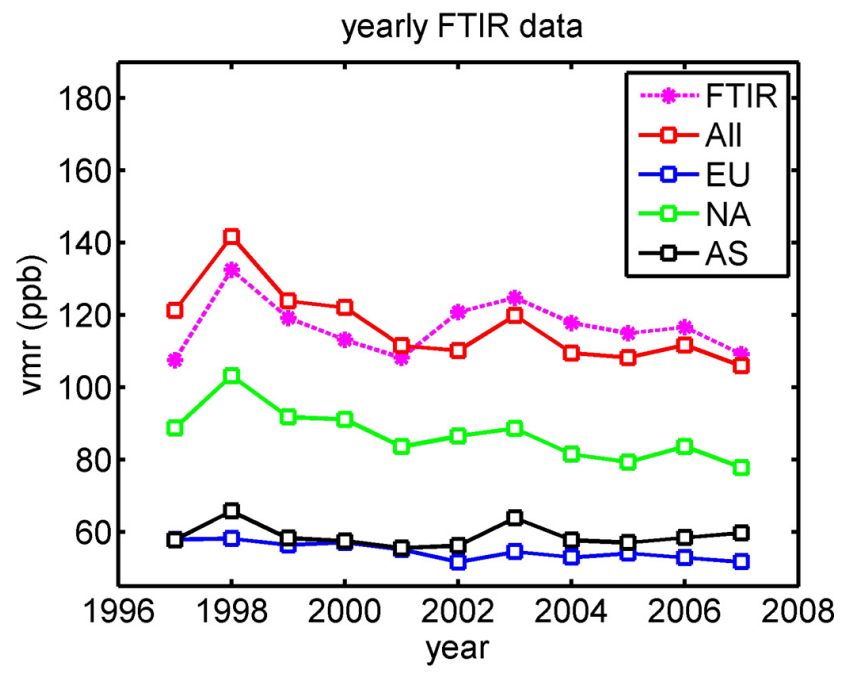

Fig. 12. Yearly mean FTIR data as well as model simulated CO concentrations above the Jungfraujoch. All, corresponds to the global model simulations, while EU, NA and AS are the model contributions from Europe, North America and Asia respectively. Again the fitted 43 ppb background has been added to all model output (also the regional ones).

increase in the importance of Asian emissions compared to the NDIR run (Fig. 11).

When we look at the year to year variability of both NDIR and FTIR simulations, we clearly see the 1998, 2003 and 2006 peaks. These are mostly driven by the North American (for NDIR) and Asian emissions. Both model runs seem to underestimate the 2002 emissions, while overestimating the 2000 values. Note that the NDIR and FTIR data used are the REBS-CNR filtered data and the year 2000 saw some of the highest in situ CO concentrations, which all have been filtered out. The overall temporal evolution of the CO concentrations is very well reproduced by the model in the NDIR case, but less so in the FTIR simulation. A crude linear fit through the modelled FTIR data yields a slope of $-3.7 \pm 0.6$ ppb year $^{-1}$. Disregarding the averaging kernel smoothing (Eq. 1), the slope would have been $-3.6 \pm 0.6 \mathrm{ppb} \mathrm{year}^{-1}$. Therefore the impact of the constant a priori content on the FTIR signal is minimal.

\section{Discussion}

The observed overall decline of NDIR CO concentrations can mainly be attributed to the steady reduction of European and North American emission sources. The EDGAR emission database shows a decrease from $50.5 \mathrm{Gt}$ to $32 \mathrm{Gt}$ between 1997 and 2005 for Central and OECD (Organisation for Economic Co-operation and Development) Europe (tagged as EU in Fig. 13). Likewise the combined USMexican emissions (tagged as NA in Fig. 13) dropped from $103 \mathrm{Gt}$ to $69.6 \mathrm{Gt}$ over the, same time frame. 


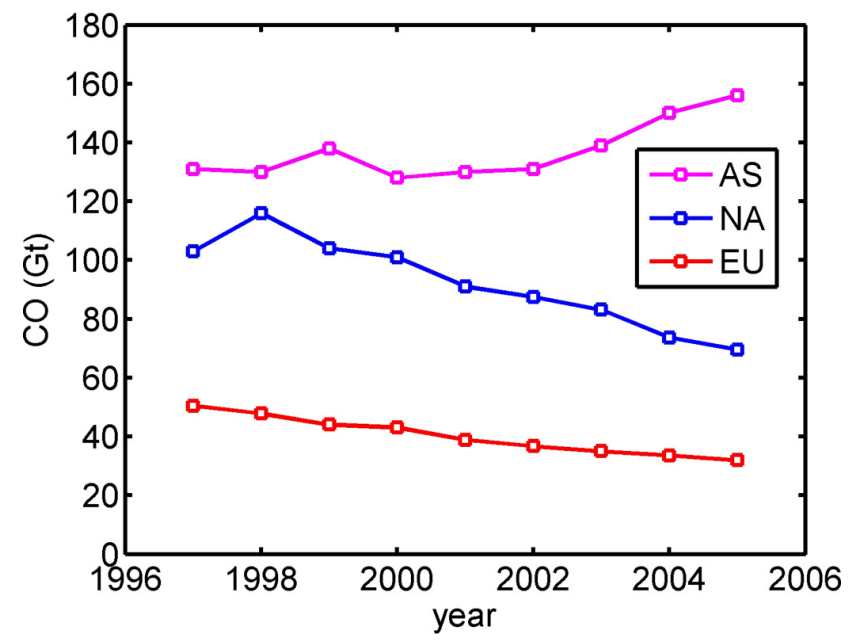

Fig. 13. CO emissions over time for AS (India + China), EU (OECD and Central Europe) and NA (USA + Mexico). Source: EC-JRC/PBL. EDGAR version 4.1. http://edgar.jrc.ec.europa.eu/, 2010.

Both EU and NA emissions decreased at a fairly constant pace, by $36.6 \%$ and $32.4 \%$ respectively, over the period 1997-2005. The combined anthropogenic emissions from India and China (the dominant Asian contributors according to Pfister et al., 2004), increased from $131 \mathrm{Gt}$ to $156 \mathrm{Gt}$ or $19 \%$ over the same time period.

However, as mentioned before, the increase in the NDIRFTIR difference looks rather gradual throughout 1998 till 2004. At least the 1997 to 2001 decrease is just as, if not more, significant as the 2001-2004 decrease. To account for the small negative FTIR trend and the influence of decreasing European and North American emissions in the FTIR signal, the Asian emissions should likewise show a gradual increase. Indeed, there is strong evidence that particularly Chinese $\mathrm{CO}$ emissions increased between 2001 and 2005. The EDGAR database shows a 78.4 to $103.6 \mathrm{Gt}(32 \%)$ increase between 2001 and 2005, while the REAS (Regional Emission Inventory in Asia) database (Ohara et al., 2007) displays a $17 \mathrm{Gt}$ increase of Chinese emissions between 2000 and 2003. However, both EDGAR and REAS show no significant increase for the 1997 to 2001 period, but a 3-4 Gt decrease. Therefore, the increase can hardly be called gradual and one would expect a much stronger evolution of the NDIR-FTIR difference after 2001. This is also reproduced in our FTIR model simulation. While the 2001-2007 period shows no significant trend for the model (in agreement with the FTIR data), the 1997 to 2001 period features a stronger trend than observed. Particularly the 1997-1998 modelled values are significantly higher than those measured by FTIR. Sure enough there is considerable uncertainty in the $\mathrm{CO}$ baseline from oxidation, as well as the exact contribution of certain source regions to the overall signal but any shift regarding these parameters will deteriorate the quality of the post 2001 fit or vice versa. Given the quality of the NDIR model fit, which adds credibility to our method, and the significant contributions from North American and European emissions sources on the NDIR signal, an overestimation of the pre-2001 Asian data (or underestimation of its positive trend) is the most likely culprit.

However, other factors might come into play as well. Given that the FTIR dataset is sparser than the NDIR dataset, it is more likely that the FTIR measurements become influenced by year to year variabilities in the average source region, which is taken as a constant in the model run. Combined with the large impact of the 1998 fires on the 19972001 CO evolution, this could potentially lead to significant over- and underestimations. However, the above would likely have a random impact, not a systematic pre- and post 2001 feature.

\section{Concluding remarks}

In this paper, we have looked into the 1997-2007 CO measurements made at the Jungfraujoch research station, using two different ground-based measurement techniques, namely NDIR in situ sampling and FTIR remote sensing. The substantial differences in sampled air masses, combined with the fact that the atmospheric life time of $\mathrm{CO}(\sim 2$ months $)$ is too short for it to be well mixed throughout the free troposphere but yet is long enough to feel the influence of far away source regions (both qualities which makes $\mathrm{CO}$ an ideal component for tracer studies), makes that substantial differences between NDIR and FTIR can arise, especially with regards to the overall trend.

The impact of background air selection methods and temporal overlap criteria has been discussed. The latter clearly showed that both techniques are still to a significant degree influenced by the same $\mathrm{CO}$ variability, as is indicated by their correlations, even on a day to day variability scale.

Kolmogorov-Zurbenko smoothing revealed the strong inter-annual variability and impact of biomass burning events on the overall trend. Both NDIR and FTIR instruments exhibited the same features although the respective impact of the episodes on the measurement signal could differ. It is also clear that underneath these features, the overall NDIR trend was significantly negative, while the FTIR signal always reverted back to its $\sim 110 \mathrm{ppb}$ background. The gradient of the NDIR-FTIR difference proved to be consistently negative apart from the year 2005-2006.

We have also shown that, for FTIR, the influence from Asian emissions is indeed much larger than for NDIR. LAGRANTO-EDGAR-GFED simulations yield excellent agreement with the NDIR measurements and also show a tempered trend in the 2001-2007 FTIR data. However, the evolution of the pre-2001 FTIR trend is less well captured by the model. Emission databases typically indicate an Asian CO increase after 2001 only. Thus, since the NDIR-FTIR 
trend difference propagates over the entire 1997-2004 period, it cannot be explained by the impact of Asian emissions alone. Whether the increasing Asian $\mathrm{CO}$ emission trend has been underestimated for the pre-2001 period, or that hitherto unknown factors play a role remains to be investigated.

Acknowledgements. We would like to thank the International Foundation High Altitude Research Stations Jungfraujoch and Gornergrat (HFSJG, Bern) for supporting the facilities needed to perform the observations. The Swiss National Air Pollution Monitoring Network is run by Empa in joint collaboration with the Swiss Federal Office for the Environment (FOEN). Work at University of Liège and BIRA-IASB was supported by the Belgian Science Policy Office (PRODEX and SSD programs) as well as by the European Commission through the GEOmon (Global Earth Observation and Monitoring) Integrated Project under the 6th Framework Program (contract number FP6-2005-Global-4-036677). We are grateful to the many Belgian colleagues who contributed to the FTIR data acquisition.

We thank MeteoSwiss for the provision of meteorological data. The NDIR and FTIR datasets are available from the WMO GAW World Data Centre for Greenhouse Gases (http://gaw.kishou.go.jp/wdcgg/) and the NDACC (ftp://ftp.cpc.ncep.noaa.gov/ndacc/station/) database, respectively.

Edited by: N. M. Donahue

\section{References}

Barret, B., De Mazière, M., and Mahieu, E.: Ground-based FTIR measurements of $\mathrm{CO}$ from the Jungfraujoch: characterisation and comparison with in situ surface and MOPITT data, Atmos. Chem. Phys., 3, 2217-2223, doi:10.5194/acp-3-2217-2003, 2003.

Clerbaux, C., George, M., Turquety, S., Walker, K. A., Barret, B., Bernath, P., Boone, C., Borsdorff, T., Cammas, J. P., Catoire, V., Coffey, M., Coheur, P.-F., Deeter, M., De Mazière, M., Drummond, J., Duchatelet, P., Dupuy, E., de Zafra, R., Eddounia, F., Edwards, D. P., Emmons, L., Funke, B., Gille, J., Griffith, D. W. T., Hannigan, J., Hase, F., Höpfner, M., Jones, N., Kagawa, A., Kasai, Y., Kramer, I., Le Flochmoën, E., Livesey, N. J., López-Puertas, M., Luo, M., Mahieu, E., Murtagh, D., Nédélec, P., Pazmino, A., Pumphrey, H., Ricaud, P., Rinsland, C. P., Robert, C., Schneider, M., Senten, C., Stiller, G., Strandberg, A., Strong, K., Sussmann, R., Thouret, V., Urban, J., and Wiacek, A.: CO measurements from the ACE-FTS satellite instrument: data analysis and validation using ground-based, airborne and spaceborne observations, Atmos. Chem. Phys., 8, 2569-2594, doi:10.5194/acp-8-2569-2008, 2008.

Cleveland, W. S.: Robust Locally Weighted Regression and Smoothing Scatterplots, J. Am. Stat. Assoc., 74, 829-836, 1979.

Cui, J., Pandey Deolal, S., Sprenger, M., Henne, S., Staehelin, J., Steinbacher, M., and Nédélec, P.: Free troposheric ozone changes over Europe as observed at Jungfraujoch (1990-2008): An analysis based on backward trajectories, J. Geophys. Res., 116, D10304, doi:10.1029/2010JD015154, 2011.

Daniel, J. S. and Solomon, S.: On the climate forcing of carbon monoxide, J. Geophys. Res. Atmos., 103, 13249-13260, 1998.
Deeter, M. N., Emmons, L. K., Francis, G. L., Edwards, D. P., Gille, J. C., Warner, J. X., Khattatov, B., Ziskin, D., Lamarque, J.-F., Ho, S.-P., Yudin, V., Attie, J.-L., Packman, D., Chen, J., Mao, D., and Drummond, J. R.: Operational carbon monoxide retrieval algorithm and selected results for the MOPITT instrument, J. Geophys. Res., 108, 4399, doi:10.1029/2002JD003186, 2003.

Deeter, M. N., Edwards, D. P., Gille, J. C., Emmons, L. K., Francis, G., Ho, S. P., Mao, D., Masters, D., Worden, H., Drummond, J. R., and Novelli, P. C.: The MOPITT version 4 CO product: Algorithm enhancements, validation, and long-term stability, J. Geophys. Res. Atmos., 115, D07306, doi:10.1029/2009JD013005, 2010.

Derwent, R., Simmonds, P., O'Doherty, S., Ciais, P., and Ryall, D.: European source strengths and northern hemisphere baseline concentrations of radiatively active trace gases at Mace Head, Ireland, Atmos. Environ., 32, 3703-3715, 1998.

De Wekker, S. F. J., Steyn, D. G., and Nyeki, S.: A comparison of aerosol layer and convective boundary layer structure over a mountain range during 97, Bound.-Layer Meteor., 113, 249-271, 2004.

Folini, D., Kaufmann, P., Ubl, S., and Henne, S.: Region of influence of 13 remote European measurement sites based on modeled carbon monoxide mixing ratios, J. Geophys. Res. Atmos., 114, D08307, doi:10.1029/2008JD011125, 2009.

Forrer, J., Ruttimann, R., Schneiter, D., Fischer, A., Buchmann, B., and Hofer, P.: Variability of trace gases at the high-Alpine site Jungfraujoch caused by meteorological transport processes, J. Geophys. Res. Atmos., 105, 12241-12251, 2000.

Gilge, S., Plass-Duelmer, C., Fricke, W., Kaiser, A., Ries, L., Buchmann, B., and Steinbacher, M.: Ozone, carbon monoxide and nitrogen oxides time series at four alpine GAW mountain stations in central Europe, Atmos. Chem. Phys., 10, 12295-12316, doi:10.5194/acp-10-12295-2010, 2010.

Hase, F., Blumenstock, T., and Paton-Walsh, C.: Analysis of the instrumental line shape of high-resolution Fourier transform IR spectrometers with gas cell measurements and new retrieval software, Appl. Optics, 38, 3417-3422, 1999.

Henne, S., Furger, M., Nyeki, S., Steinbacher, M., Neininger, B., de Wekker, S. F. J., Dommen, J., Spichtinger, N., Stohl, A., and Prévôt, A. S. H.: Quantification of topographic venting of boundary layer air to the free troposphere, Atmos. Chem. Phys., 4, 497509, doi:10.5194/acp-4-497-2004, 2004.

Henne, S., Brunner, D., Folini, D., Solberg, S., Klausen, J., and Buchmann, B.: Assessment of parameters describing representativeness of air quality in-situ measurement sites, Atmos. Chem. Phys., 10, 3561-3581, doi:10.5194/acp-10-3561-2010, 2010.

Holloway, T., Levy, H., and Kasibhatla, P.: Global distribution of carbon monoxide, J. Geophys. Res. Atmos., 105, 12123-12147, 2000.

Levy, H., Kasibhatla, P. S., Moxim, W. J., Klonecki, A. A., Hirsch, A. I., Oltmans, S. J., and Chameides,W. L.: The global impact of human activity on tropospheric ozone, Geophys. Res. Lett., 24, 791-794, 1997.

Logan, J. A., Prather, M. J.,Wofsy, S. C., and McElroy, M. B.: Tropospheric Chemistry - a Global Perspective, J. Geophys. Res.Oceans and Atmospheres, 86, 7210-7254, 1981.

Luterbacher, J., Dietrich, D., Xoplaki, E., Grosjean, M., and Wanner, H.: European seasonal and annual temperature variability, trends, and extremes since 1500, Science, 303, 1499-1503, 2004. 
Novelli, P. C., Masarie, K. A., and Lang, P. M.: Distributions and recent changes of carbon monoxide in the lower troposphere, J. Geophys. Res. Atmos., 103, 19015-19033, 1998.

Nyeki, S., Kalberer, M., Colbeck, I., De Wekker, S., Furger, M., Gäggeler, H.W., Kossmann, M., Lugauer, M., Steyn, D., Weingartner, E., Wirth, M., and Baltensperger, U. : Convective Boundary Layer Evolution to $4 \mathrm{~km}$ als over High-Alpine Terrain: Airborne Lidar Observations in the Alps, Geophys. Res. Lett., 27, 689-692, 2000.

O’Doherty, S., Simmonds, P., Cunnold, D., Wang, H., Sturrock, G., Fraser, P., Ryall, D., Derwent, R., Weiss, R., Salameh, P., Miller, B., and Prinn, R.: In situ chloroform measurements at AdvancedGlobal Atmospheric Gases Experiment atmospheric research stations from 1994 to 1998, J. Geophys. Res., 106, 20429-20444, 2001.

Ohara, T., Akimoto, H., Kurokawa, J., Horii, N., Yamaji, K., Yan, X., and Hayasaka, T.: An Asian emission inventory of anthropogenic emission sources for the period 1980-2020, Atmos. Chem. Phys., 7, 4419-4444, doi:10.5194/acp-7-4419-2007, 2007.

Pfister, G., Petron, G., Emmons, L. K., Gille, J. C., Edwards, D. P., Lamarque, J. F., Attie, J. L., Granier, C., and Novelli, P. C.: Evaluation of $\mathrm{CO}$ simulations and the analysis of the CO budget for Europe, J. Geophys. Res. Atmos., 109, D19304, doi:10.1029/2004JD004691, 2004.

Reimann, S., Vollmer, M. K., Folini, D., Steinbacher, M., Hill, M., Buchmann, B., Zander, R., and Mahieu, E.: Observations of Anthropogenic Halocarbons at the High-Alpine site of Jungfraujoch for assessment of trends and European sources, Sci. Tot. Environ., 391, 224-231, 2008.

Rodgers, C. D.: Retrieval of atmospheric temperature and composition from remote measurements of thermal radiation, Rev. Geophys. Space Phys., 14(4), 609-624, 1976.

Rodgers, C. D.: Characterisation and error analysis of profiles retrieved from remote sounding measurements, J. Geophys. Res., 95, 5587-5595, 1990.

Rodgers, C. D.: Inverse methods for atmospheric sounding: Theory and Practice, Series on Atmospheric, Oceanic and Planetary Physics - Vol. 2, World Scientific, 2000.

Rothman, L. S., Barbe, A., Benner, D. C., Brown, L. R., CamyPeyret, C., Carleer, M. R., Chance, K., Clerbaux, C., Dana, V., Devi, V. M., Fayt, A., Flaud, J.-M., Gamache, R. R., Goldman, A., Jacquemart, D., Jucks, K. W., Lafferty, W. J., Mandin, J.-Y., Massie, S. T., Nemtchinov, V., Newnham, D. A., Perrin, A., Rinsland, C. P., Schroeder, J., Smith, K. M., Smith, M. A. H., Tang, K., Toth, R. A., Vander Auwera J., Varanasi, P., and Yoshino, K.: The HITRAN Molecular Spectroscopic Database: Edition 2000 including Updates through 2001, J. Quant. Spectrosc. Radiat. Transfer, 82, 5-44, 2003.

Ruckstuhl, A. F., Henne, S., Reimann, S., Steinbacher, M., Buchmann, B., and Hueglin, C.: Robust extraction of baseline signal of atmospheric trace species using local regression, Atmos. Meas. Tech. Discuss., 3, 5589-5612, doi:10.5194/amtd-3-55892010, 2010.

Simmonds, P. G., Manning, A. J., Derwent, R. G., Ciais, P., Ramonet, M., Kazan, V., and Ryall, D.:. A burning question. Can recent growth rate anomalies in greenhouse gases be attributed to large-scale biomass burning events?, Atmos. Environ., 39, 2513$2517,2005$.
Tressol, M., Ordonez, C., Zbinden, R., Brioude, J., Thouret, V., Mari, C., Nedelec, P., Cammas, J.-P., Smit, H., Patz, H.-W., and Volz-Thomas, A.: Air pollution during the 2003 European heat wave as seen by MOZAIC airliners, Atmos. Chem. Phys., 8, 2133-2150, doi:10.5194/acp-8-2133-2008, 2008.

van der Werf, G. R., Randerson, J. T., Giglio, L., Collatz, G. J., Mu, M., Kasibhatla, P. S., Morton, D. C., DeFries, R. S., Jin, Y., and van Leeuwen, T. T.: Global fire emissions and the contribution of deforestation, savanna, forest, agricultural, and peat fires (19972009), Atmos. Chem. Phys., 10, 11707-11735, doi:10.5194/acp10-11707-2010, 2010.

Wernli, H. and Davies, H. C.: A Lagrangian-based analysis of extratropical cyclones. I: The method and some applications., Q. J. Roy. Meteorol. Soc., 123, 467-489, 1997.

Wild, O. and Prather, M. J.: Excitation of the primary tropospheric chemical mode in a global three-dimensional model, J. Geophys. Res. Atmos., 105, 24647-24660, 2000.

World Meteorological Organisation: Guide to Meteorological Instruments and Methods of Observations, WMO-No. 8 (Seventh edition), 2008.

Yurganov, L. N., Blumenstock, T., Grechko, E. I., Hase, F., Hyer, E. J., Kasischke, E. S., Koike, M., Kondo, Y., Kramer, I., Leung, F.-Y., Mahieu, E., Mellqvist, J., Notholt, J., Novelli, P. C., Rinsland, C. P., Scheel, H. E., Shultz, A., Strandberg, A., Sussmann, R., Tanimoto, H., Velazco, V., Zander, R., and Zhao, Y.: A Quantitative Assessment of the 1998 Carbon Monoxide Emission Anomaly in the Northern Hemisphere Based on Total Column and Surface Concentration Measurements, J. Geophys. Res., 109(D15), D15305, doi:10.1029/2004JD004559, 2004.

Yurganov, L. N., Duchatelet, P., Dzhola, A. V., Edwards, D. P., Hase, F., Kramer, I., Mahieu, E., Mellqvist, J., Notholt, J., Novelli, P. C., Rockmann, A., Scheel, H. E., Schneider, M., Schulz, A., Strandberg, A., Sussmann, R., Tanimoto, H., Velazco, V., Drummond, J. R., and Gille, J. C.: Increased Northern Hemispheric carbon monoxide burden in the troposphere in 2002 and 2003 detected from the ground and from space, Atmos. Chem. Phys., 5, 563-573, doi:10.5194/acp-5-563-2005, 2005.

Zander, R., Demoulin, P., Ehhalt, D. H., Schmidt, U., and Rinsland, C. P.: Secular Increase of the Total Vertical Column Abundance of Carbon-Monoxide above Central-Europe since 1950, J. Geophys. Res. Atmos., 94, 11021-11028, 1989.

Zander, R., Mahieu, E., Demoulin, P., Duchatelet, P., Roland, G., Servais, C., Maziere, M. D., Reimann, S., and Rinsland, C. P.: Our changing atmosphere: Evidence based on long-term infrared solar observations at the Jungfraujoch since 1950, Sci. Total Environ., 391, 184-195, 2008.

Zellweger, C., Forrer, J., Hofer, P., Nyeki, S., Schwarzenbach, B., Weingartner, E., Ammann, M., and Baltensperger, U.: Partitioning of reactive nitrogen $\left(\mathrm{NO}_{\mathrm{y}}\right)$ and dependence on meteorological conditions in the lower free troposphere, Atmos. Chem. Phys., 3, 779-796, doi:10.5194/acp-3-779-2003, 2003.

Zellweger, C., Hüglin, C., Klausen, J., Steinbacher, M., Vollmer, M., and Buchmann, B.: Inter-comparison of four different carbon monoxide measurement techniques and evaluation of the long-term carbon monoxide time series of Jungfraujoch, Atmos. Chem. Phys., 9, 3491-3503, doi:10.5194/acp-9-3491-2009, 2009.

Zurbenko, I. G.: The spectral Analysis of Time Series. NorthHolland, 248 pp., 1986. 